\section{Dental education}

\section{Is Black Lives Matter over now?}

Sir, I am a third-year dental student at Queen Mary's University London. As a student that is enthusiastic about dental education, I am constantly observing and reflecting on areas that require change. While the focus on the Black Lives Matter (BLM) movement has subsided, with fewer local demonstrations and reduced media coverage, it does not mean that my passion for equality has also diminished.

From my perspective, the problems in dentistry are two-fold. Firstly, the underrepresentation of black dental professionals within the workforce. Secondly, unconscious bias, where the consequences are evident in areas from dental education to the recognition of clinical manifestations of diseases, leading to delayed and missed diagnoses.

More role models will pave the way for future black dentists. But why is it that in 2014, when 3,410 prospective students applied to dentistry, of the 135 black students only 25 were accepted (19\% acceptance rate)? This compares with 460 accepted Asian applicants (40.9\%) and 549 accepted white applicants (54.1\%). ${ }^{1}$ These results highlight the risks of not separating the terms 'BAME' and 'black' in dentistry.

Under-representation consequently plays a part in clinical diagnosis. Low numbers of black academics and specialists limits the research, educational teaching and overall momentum on how skin colour affects the clinical manifestation of diseases.

Fortunately, I do believe change and adaptation is happening in dentistry. Medics are also taking a structured and academic approach, with a new handbook due out on the presentation of different skin diseases written by a medical student at St George's University London. ${ }^{2}$ The oral mucosa is not exempt in this, with racial pigmentation being misdiagnosed and delayed recognition of herpes labialis and Kaposi's sarcoma.

Social media is helping communities to grow, such as 'Melanin Medics,' 'Black Budding Dentists' and the African \& Caribbean Dental Association (ACDA). These have united, encouraged and inspired young black dentists and potential dental school applicants.

In July 2020, I, along with five other black dental students were invited to meet with the GDC's Head of Education, Head of Research and Head of Policy to discuss our views and concerns. This positive recognition with active listening and suggestions for improvement, felt like dentistry is finally reacting to the BLM movement.

BLM isn't over now, with changes occurring in our dental schools, the GDC, medical education and in our dental CPD. I ask of the GDPs up and down the UK, to reflect on their own impact within the dental community and consider engaging in verifiable online CPD webinars, discussions and articles investigating and bringing light to problems that exist with diversity and equality.

In order to sustain the momentum in striving for equality and the highest standard of care, we must commit to this form of lifelong learning. I'm sure dental professionals will be eager to understand more about the specific problems that manifest from a group of under-represented individuals. Together with my peers, we shall continue to research and actively work on these barriers in dentistry, thus striving for equality.

T. Kadiyo, V. Mellish, London, UK

\section{References}

1. Gallagher J E, Calvert A, Niven V, Cabot L. Do high tuition fees make a difference? Characteristics of applicants to UK medical and dental schools before and after the introduction of high tuition fees in 2012. Br Dent J 2017; 222: 181-190.

2. Rimmer A. Presenting clinical features on darker skin: five minutes with ... Malone Mukwende. BMJ 2020; 369: m2578. doi: 10.1136/bmj.m2578.

https://doi.org/10.1038/s41415-020-2184-4

\section{Diminished impact}

Sir, we read the paper on dental core training with interest given the premise is important. ${ }^{1}$ Understanding the motivation for undertaking non-compulsory training assists in programme development and ensures that it aligns with future career intentions. Unfortunately, the impact of this paper is diminished by the misreporting of the survey data.

Within the results section, the narrative contradicts the data presented within the figures. For example, Figures 4 and 5 graphically represent the survey responses, indicating that the majority felt the SJT was fair and realistic (78.7\%) and 37.2\% felt it beneficial to the application process. This is at odds with the authors' interpretation that $47.6 \%$ of respondents felt that the SJT was beneficial to the application and ranking process, only $9.3 \%$ felt it was fair, representable and realistic'. It is reassuring to see the findings represented within the figures align with previously published data, ${ }^{2,3,4}$ including DCT specific research, ${ }^{5}$ which reported that $79.8 \%$ felt the SJT content fair and $84.2 \%$ considered it relevant. There is an implication in the paper that applicants do not regard the SJT as valuable and that 'the majority of the situations have never and would never arise'. It is important to highlight the robust national development process ${ }^{2}$ with clinician and other stakeholder involvement throughout, which ensures the SJT content is relevant to the role.

Additional reporting or interpretation errors include how applicants' preference training posts were based on geography: Figure 9 implies $41.5 \%$ of applicants were prepared to accept a post in any location, while this is interpreted as $53.0 \%$. This contrasts with only $4.4 \%$ reporting that they based their selection on the job description (Fig. 10; interpreted as $89.1 \%$ ). It is perceived that this is linked to the $38.3 \%$ of trainees reporting inadequate teaching/learning experience (data from Fig. 12; though 39.4\% is reported in the text) and could possibly explain the $39.3 \%$ intending to exit the programme. If applicants preference solely on location it is not surprising that they are less satisfied with the overall learning experience. While this is not expanded on within the discussion, it is an opportunity for continued programme review and improvement.

Overall, this paper highlights issues impacting on the quality of the DCT programme. Unfortunately, the misreporting of the survey data devalues the impact and leaves us questioning the conclusions drawn. Therefore, we raise concern that this paper will be accepted as a definitive exploration of a set of complex issues, which in its current format, is likely to mislead readers.

F. Patterson, E. Morley, J. Bird, E-L. Rowe, Work Psychology Group, UK, A. Dickenson, Health Education East Midlands, UK

The authors, Christopher C. Donnell and Jennifer I. Foley, respond: We thank Professor Patterson and her colleagues for recognising the importance of our recent research into the motivation, perception and experience of recently-qualified graduates in the pursuit of dental core training. As we would all concur, recruitment to educational opportunities should be robust, transparent and fair with an evidence-based approach to the selection process. 